\title{
Effect of exogenous stress factors on the biosynthesis of carotenoids and lipids by Rhodotorula yeast strains in media containing agro-industrial waste
}

\author{
Anna M. Kot ${ }^{1}(\mathbb{D}) \cdot$ Stanisław Błażejak ${ }^{1} \cdot$ Marek Kieliszek$^{1} \cdot$ Iwona Gientka $^{1} \cdot$ Joanna Bryś $^{2} \cdot$ Lidia Reczek $^{3}$. \\ Katarzyna Pobiega ${ }^{1}$
}

Received: 26 June 2019 / Accepted: 25 September 2019 / Published online: 1 October 2019

(c) The Author(s) 2019

\begin{abstract}
In this study, we aimed to determine the effect of exogenous stress factors (sodium chloride as osmotic stressor, hydrogen peroxide as an inducer of oxidative stress, white light irradiation, and low temperature) on the biosynthesis of carotenoids and lipids by red yeast (Rhodotorula glutinis, $R$. mucilaginosa, and $R$. gracilis) during cultivation in media containing potato wastewater and glycerol. According to our results, the yeast were able to grow and biosynthesize lipids and carotenoids in the presence of the applied stress factors. Low temperature caused an increase in the biosynthesis of intracellular lipids and carotenoids. $R$. gracilis synthesized lipids $\left(21.1 \mathrm{~g} / 100 \mathrm{~g}_{\text {d.w. }}\right)$ and carotenoids $\left(360.4 \mu \mathrm{g} / \mathrm{g}_{\text {d.w. }}\right)$ in greater quantities than that of other strains. Under these conditions, there was also an increase in the content of unsaturated fatty acids, especially linoleic and linolenic acids. The highest percentage of polyunsaturated fatty acid (PUFA) (30.4\%) was synthesized by the R. gracilis yeast after cultivation at $20^{\circ} \mathrm{C}$. Their quantity was 2.5 -fold greater than that of the biomass grown in control conditions. The contribution of individual carotenoid fractions depended both on the yeast strain and the culture conditions. Induction of osmotic stress and low temperature intensified the biosynthesis of $\beta$-carotene (up to $73.9 \%$ of the total carotenoid content). In oxidative stress conditions, yeast synthesized torulene (up to $82.2 \%$ ) more efficiently than under other conditions, whereas white light irradiation increased the production of torularhodin (up to $20.0 \%$ ).
\end{abstract}

Keywords Red yeast $\cdot \mathrm{SCO} \cdot$ Carotenoids $\cdot$ Osmotic stress $\cdot$ Oxidative stress $\cdot$ Irradiation

\section{Introduction}

Yeast belonging to the genus Rhodotorula have been described as oleaginous microorganisms. Under specific conditions, these microorganisms can synthesize lipids up to $20 \%$ of their dry cellular weight (Kot et al. 2015). They can

Electronic supplementary material The online version of this article (https://doi.org/10.1007/s11274-019-2732-8) contains supplementary material, which is available to authorized users.

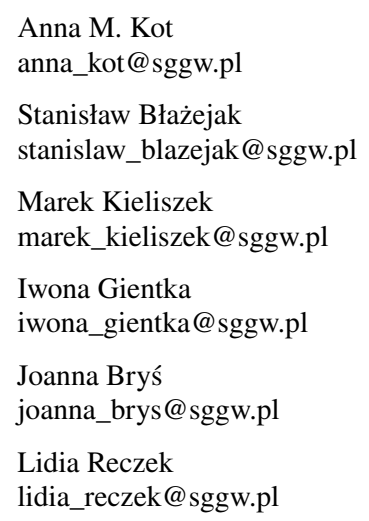

Katarzyna Pobiega

katarzyna_pobiega@sggw.pl

1 Department of Biotechnology, Microbiology and Food Evaluation, Faculty of Food Sciences, Warsaw University of Life Sciences, Nowoursynowska 159C, 02-776 Warsaw, Poland

2 Department of Chemistry, Faculty of Food Sciences, Warsaw University of Life Sciences, Nowoursynowska 159C, 02-776 Warsaw, Poland

3 Department of Civil Engineering, Faculty of Civil and Environmental Engineering, Warsaw University of Life Sciences, Nowoursynowska 159, 02-776 Warsaw, Poland 
also biosynthesize carotenoids such as $\beta$-carotene, torulene, and torularhodin, which gives them a striking reddish-pink color appearance. Due to this property, they are described as "red yeast" (Kot et al. 2018). The production of lipids and carotenoids with the utilization of microbiological methods show greater advantages than conventional means, such independence from weather conditions, season, geographical location, and availability of agricultural land. Furthermore, microorganisms demonstrate a rapid rate of growth, which significantly shortens the production cycle. However, the only obstacle for a successful production output is the low yield per unit volume of the medium, which greatly increases the cost of the process (Frengova and Beshkova 2009; Kot et al. 2015).

The content of lipids and carotenoids in yeast cells of the genus Rhodotorula depends on many factors, such as the source of carbon and nitrogen, presence of microelements in the medium, rate of aeration, and temperature of cultivation (Kot et al. 2016, 2018). However, the biosynthesis of lipids and carotenoids by the yeast cells can be intensified by adding various chemical inducers to the culture medium and by changing the environmental conditions of the culture. These changes are described as stressful conditions, for example, change in temperature, visible or ultraviolet light irradiation, an increase in osmotic pressure (e.g., high concentrations of sodium chloride, sugars, and glycerol), presence of toxic substances (e.g., heavy metal salts, phenol, and methylene blue), and presence of oxidative stress (Sakaki et al. 2001; Bhosale and Gadre 2002; Bhosale 2004; Frengova and Beshkova 2009; Amaretti et al. 2010; Zhang et al. 2014). In response to unfavorable environmental conditions, microbial cells show an increased expression of genes that code for the production of enzymes that are involved in the biosynthesis of various compounds, including lipids and carotenoids (Marova et al. 2012). Due to the presence of these stress-responsive mechanisms, yeasts not only can tolerate higher doses of a given factor after but also other components that can cause stress (Sigler et al. 1999).

Therefore, in this study, we aimed to determine the effect of exogenous stress factors on the biosynthesis of carotenoids and lipids by Rhodotorula glutinis LOCKR13, $R$. mucilaginosa ATCC 66034, and R. gracilis ATCC 10788 yeast. Among the many stress factors presented in the literature four were selected: sodium chloride as osmotic stressor, hydrogen peroxide as an inducer of oxidative stress, white light irradiation, and low temperature. These factors are easy to apply, cheap, do not cause genetic modification and simultaneously can effectively intensify the biosynthesis of lipids and/or carotenoids by yeasts of the genus Rhodotorula. To reduce costs, the culture media were prepared exclusively from two industrial wastes. Glycerol fraction was used as the carbon source, and deproteinized potato wastewater was used as a source of nitrogen and minerals.

\section{Materials and methods}

\section{Biological material}

In this study, we used R. mucilaginosa ATCC 66034 and $R$. gracilis ATCC 10788 strains obtained from the American Type Culture Collection and R. glutinis LOCKR13 strain obtained from the Collection of Pure Cultures of the Lodz University of Technology in Poland.

\section{Industrial wastes used as components of media}

Glycerol fraction from the production of biodiesel (Bioagra-Oil S.A., Tychy, Poland) was used to prepare the growing media. The content of glycerol was established by a chemical method (Milchert et al. 1995). The content of glycerol was determined by GC-MS (Shimadzu, GCMS-QP2010S) using HP-INNOWax capillary column $(30 \mathrm{~m} \times 0.25 \mathrm{~mm} \times 0.25 \mu \mathrm{m}$; Industrial Chemistry Research Institute, Warsaw). The content of selected mineral was determined by inductively coupled plasma atomic emission spectroscopy (ICP-AES) (Thermo iCAP 6500) in the Analytical Center of WULS, Warsaw. These analyses are described in detail in our previous article (Kot et al. 2019). Glycerol fraction contained: $60.3 \%$ glycerol, $3.3 \%$ methanol, $1.1 \%$ sodium, $0.024 \%$ calcium, $0.007 \%$ potassium, $0.004 \%$ phosphorus, and $0.003 \%$ magnesium and had a pH of 12.1 .

Deproteinized potato wastewater was used as the source of nitrogen and minerals, and was prepared in laboratory conditions according to the methodology described in the previous work (Kot et al. 2017). The total nitrogen and protein content were determined using the Kjeldahl method with a conversion factor of 6.25 (Kirk 1950). The content of reducing sugars (per glucose) was measured spectrophotometrically at $\lambda=550 \mathrm{~nm}$ using 3,5-dinitrosalicylic acid (Miller 1959). The chemical oxygen demand index was assessed by the dichromate method using Hach Lange cuvette tests (LCK014) in the Water Centre of the Warsaw University of Life Sciences. Potato wastewater contained $1.98 \mathrm{~g} / \mathrm{L}$ nitrogen, $12.4 \mathrm{~g} / \mathrm{L}$ total protein, and $8.3 \mathrm{~g} / \mathrm{L}$ reducing sugars and was characterized by a high index value of chemical oxygen demand (COD) $\left(29,846 \mathrm{mg} \mathrm{O}_{2} / \mathrm{L}\right)$.

\section{Preparation of the inoculum}

The yeast inoculum was prepared by inoculating the liquid yeast extract-peptone-dextrose (YPD) medium ( $20 \mathrm{~g} / \mathrm{L}$ glucose, $20 \mathrm{~g} / \mathrm{L}$ peptone, $10 \mathrm{~g} / \mathrm{L}$ yeast extract, $\mathrm{pH}$ 5.0) with the material obtained from the agar slants. The cultures were grown on a reciprocating shaker with a frequency of $200 \mathrm{rpm}$ (SM-30 Control, Edmund Bühler) at $28^{\circ} \mathrm{C}$ for $24 \mathrm{~h}$. One 
milliliter of inoculum contained $5 \times 10^{6} \mathrm{CFU}$. Culture media were inoculated with yeast inoculum constituting $10 \%$ of the culture volume.

\section{Cultivation of control cultures}

The control cultures were prepared in a medium with deproteinized potato wastewater supplemented with glycerol fraction such that the final concentration of glycerol in the medium was $30 \mathrm{~g} / \mathrm{L}$. The final $\mathrm{pH}$ of the medium was 5.0 (Kot et al. 2019). Ten milliliters of inoculation cultures were centrifuged (3500 $\times g / 10 \mathrm{~min}$, Centrifuge 5804R, Eppendorf) and washed twice with sterile demineralized water. The yeast biomass was then suspended in $10 \mathrm{~mL}$ of sterile culture medium, mixed thoroughly and added to $90 \mathrm{~mL}$ of medium in flat-bottomed flasks. One milliliter of inoculated culture medium contained approximately $5 \times 10^{5} \mathrm{CFU}$. The cultures were grown in $500 \mathrm{~mL}$ flat-bottomed flasks (contained $100 \mathrm{~mL}$ of medium) on a reciprocating shaker (SM-30 Control, Edmund Bühler) with a frequency of $200 \mathrm{rpm}$ at $28^{\circ} \mathrm{C}$ for $120 \mathrm{~h}$.

\section{Cultivation of cultures with exogenous stress factors}

To determine the effect of low temperature, the cultures were grown at $20^{\circ} \mathrm{C}$. The effect of white light irradiation on the growth of yeast strains was tested using illumination equipment, in which the illuminating element consisted of OSRAM Fluora bulbs (power of $18 \mathrm{~W}$, a beam of light of $550 \mathrm{~lm}$ and a wavelength ranging from 400 to $800 \mathrm{~nm}$ ). To determine the effect of increased osmotic pressure, sodium chloride $(50 \mathrm{~g} / \mathrm{L})$ was added to the growing medium. Finally, to determine the effect of oxidative stress, the yeast cultures were grown in the presence of $5 \mathrm{mM} \mathrm{H}_{2} \mathrm{O}_{2}$ in the growing media. Tests were performed at $28^{\circ} \mathrm{C}$, except in case of the temperature test.

\section{Analysis of growth of yeast}

To evaluate the growth of yeast in the presence of various stress factors, the yield in the cellular biomass was determined by the gravimetric method. Ten milliliters of culture medium was centrifuged for $10 \mathrm{~min}$ at $6000 \times g$ (Centrifuge 5804R, Eppendorf), and then the biomass was washed twice with sterile deionized water. The wet cell biomass was dried at $105^{\circ} \mathrm{C}$ until a constant weight was obtained. The results were calculated in grams of dry weight per liter of culture medium $\left(\mathrm{g}_{\text {d.w. }} / \mathrm{L}\right)$.

\section{Analysis of media composition}

In order to analyze of media composition after yeast cultures, the analytical methods described in subsection 'Industrial wastes used as components' of media were used.

\section{Estimation of lipids in yeast biomass and fatty acid profile}

The lipid content in yeast cell biomass was determined by the modified Bligh and Dyer method. To lysed the yeast cell wall, the dried biomass was subjected to acid hydrolysis $\left(1 \mathrm{M}\right.$ hydrochloric acid, $\left.60^{\circ} \mathrm{C}, 2 \mathrm{~h}\right)$. Then, the lipids were extracted with a mixture of chloroform and methanol $(1: 1 \mathrm{v} / \mathrm{v})$, and the samples were centrifuged $(3500 \times g / 10 \mathrm{~min})$. The lower phase was collected, and the lipid content in the yeast biomass was determined gravimetrically (Zhang et al. 2011). The percentage fraction of fatty acids in the extracted lipids was determined by gas chromatography (TRACETM 1300 , Thermo Scientific, USA) equipped with a flame ionization detector (FID). The fatty acids were esterified with $2 \mathrm{M} \mathrm{KOH}$ in methanol. The separation was conducted on an RTX-2330 capillary column $(60 \mathrm{~m} \times 0.25 \mathrm{~mm} \times 0.2 \mu \mathrm{m}$, Restek, USA). The temperature of the chromatographic oven was set at $50^{\circ} \mathrm{C}$ (3 min), with a rate of increase in temperature of $3^{\circ} \mathrm{C} / \mathrm{min}$ up to $250^{\circ} \mathrm{C}(5 \mathrm{~min})$. Nitrogen was used as the carrier gas $(1.6 \mathrm{~mL} / \mathrm{min})$. The injection temperature was set at $230^{\circ} \mathrm{C}$ and FID was set at $260^{\circ} \mathrm{C}$. The identification of fatty acids was performed based on the retention times of $\mathrm{Nu}$-ChekPrep Inc. standards (USA) present in the GLC 461 mixture (fatty acid esters from C4:0 to C24:0).

\section{Estimation of carotenoids in yeast biomass and their profile}

Determination of the total carotenoid content in yeast biomass was performed by spectrophotometric method. Briefly, the yeast cell wall was lysed with dimethyl sulfoxide (Cutzu et al. 2013). The carotenoids were extracted with a mixture of petroleum ether and acetone $(1: 1 \mathrm{v} / \mathrm{v})$, and the absorbance of the colored ether layer was measured at $\lambda=457 \mathrm{~nm}$ (UV1800 spectrophotometer, Rayleigh). The total carotenoid content in yeast cell biomass was calculated from the standard curve prepared for the $\beta$-carotene standard solutions and was given in microgram per gram of dry matter.

Percentage fractions of $\beta$-carotene, torulene, and torularhodin were determined by high-performance liquid chromatography (Agilent 1200 Series, Palo Alto, CA, USA) with a UV-Vis detector $(457 \mathrm{~nm})$. Bionacom C18-2 analytical column $(250 \mathrm{~mm} \times 4.6 \mathrm{~mm}, 5 \mu \mathrm{m})$ was used for the separation phase. The mobile phase contained a mixture of acetonitrile, isopropanol, and ethyl acetate in a ratio of $4: 4: 2$ by volume, and the flow rate was adjusted to $0.7 \mathrm{~mL} / \mathrm{min}$ (isocratic). We identified $\beta$-carotene based on the retention time of the standard (Sigma-Aldrich). Torulene and torularhodin standards were identified by thin-layer liquid chromatography (TLC) [Kot et al. 2017]. 


\section{Statistical analysis}

All tests were performed in triplicates. The results were analyzed using the statistical program in the $\mathrm{R}$ program (version i386 2.15.3, RCommander tab) specifying the normal distribution of data (Shapiro-Wilk test), homogeneity of variance (Levene test), and significance of differences between averages (one-way analysis of variance and Tukey's test) at the significance level of $\alpha=0.05$. $R$ scripts used for the statistical analysis has been included in the supplementary material (Table S1).

\section{Results}

The present study aimed to increase the intracellular concentration of lipids and carotenoids in the biomass of the Rhodotorula yeast strains by enhancing the biosynthesis of these compounds by the application of various stress factors. Based on the results of our previous research [Kot et al. 2019], we selected potato wastewater and 3\% glycerol as the basal medium. Under these conditions, Rhodotorula yeast proliferated rapidly and metabolized the compounds present in the medium. The cultivation of yeast strains in this medium resulted in greater reduction in COD value and utilization of nitrogen compounds and glycerol when compared to the other tested media. However, the content of intracellular lipids and carotenoids did not exceed $20 \mathrm{~g} / 100$ $\mathrm{g}_{\text {d.w. }}$ and $230 \mu \mathrm{g} / \mathrm{g}_{\text {d.w. }}$, respectively. Therefore, this study was carried out to increase the content of these compounds in the Rhodotorula yeast biomass.

In this study, the yeast belonging to the genus Rhodotorula showed the ability to grow under oxidative stress, osmotic stress, irradiation, and at low temperature. Rhodotorula glutinis yeast was sensitive to the high level of osmotic stress in the culture medium (Figure S1). After $120 \mathrm{~h}$ of cultivation, the yield of cellular biomass of $R$. glutinis was two times lower $\left(11.2 \mathrm{~g}_{\mathrm{d} w} / \mathrm{L}\right)$ than that of $R$. mucilaginosa and $R$. gracilis (20.3 and $22.0 \mathrm{~g}_{\mathrm{d} w \mathrm{w}} / \mathrm{L}$, respectively). Exogenous stress factors differentiated the growth of $R$. mucilaginosa yeast within $48 \mathrm{~h}$ of cultivation (Figure S2). However, after $120 \mathrm{~h}$ of cultivation, the yield of cellular biomass of $R$. mucilaginosa was similar to the $48 \mathrm{~h}$ cultivation (21.4 and $21.9 \mathrm{~g}_{\text {d.w. }} / \mathrm{L}$, respectively). Among the studied strains, $R$. gracilis was the most sensitive to the applied stress factors. The presence of osmotic stress or oxidative stress inhibited the growth of $R$. gracilis after $24 \mathrm{~h}$ of cultivation. A similar effect was observed in cultures after irradiation (Figure S3). Reducing the temperature from 28 to $20^{\circ} \mathrm{C}$ during the cultivation increased the rate of growth of $R$. gracilis yeast in the first days of culture. After $120 \mathrm{~h}$ of cultivation, the yield of cellular biomass of $R$. gracilis yeast was significantly lower in media containing $5 \% \mathrm{NaCl}\left(19.0 \mathrm{~g}_{\text {d.w. }} / \mathrm{L}\right)$ and $5 \mathrm{mM} \mathrm{H}_{2} \mathrm{O}_{2}$ $\left(15.2 \mathrm{~g}_{\text {d.w. }} / \mathrm{L}\right)$. In the remaining cultures biomass yields were from 20.5 to $21.4 \mathrm{~g}_{\text {d.w. }} / \mathrm{L}$.

In control and experimental conditions, yeast showed the ability to assimilate glycerol, as well as sugars and nitrogenous compounds present in the potato wastewater. The amount of utilization of these ingredients from the media was dependent on the growth of yeast. Glycerol was utilized by over $96 \%$ except cultivation of $R$. gracilis yeast under oxidative stress $(61 \%)$ and $R$. glutinis under the presence of osmotic stress. In this case the total rate of utilization of glycerol was just over 19\% (Table S1). For these variants, the rate of utilization of nitrogenous compounds from the media was significantly lower (32-44\%) than that of other (50-66\%) compounds. The residue probably contained nitrogen compounds in the form that the yeast strains were not able to assimilable or was composed of secondary yeast metabolites such as ammonia. The reducing sugars present in the potato wastewater were effectively utilized by yeast (up to $87 \%$ ). The remaining sugars could be galactose and rhamnose, which are used as carbon sources only by some of the strains belonging to the genus Rhodotorula [Fell and Statzell-Tallman 1998; Kot et al. 2019].

The ability of Rhodotorula yeast to biodegrade deproteinized potato wastewater and glycerol fraction was determined by measuring the COD index of the culture media. According to the results (Table S1), both types of industrial wastes were partially utilized by yeasts. After $120 \mathrm{~h}$ of cultivation, the COD values of the culture media decreased by $70-83 \%$, which amounted to $10,873-18,880 \mathrm{mg} \mathrm{O} \mathrm{O}_{2} / \mathrm{L}$. The only exceptions were $R$. glutinis yeast cultures grown under osmotic stress $\left(42,530 \mathrm{mg} \mathrm{O}_{2} / \mathrm{L}\right)$ and $R$. gracilis cultures grown under oxidative stress conditions $\left(24,273 \mathrm{mg} \mathrm{O}_{2} / \mathrm{L}\right)$. This was due to a significant reduction in glycerol metabolism under these conditions. As in our previous studies (Kot et al. 2019), it was not possible to reduce the COD value to a level that would enable the utilization of these post-culture media in natural conditions in accordance with the requirements of the Regulation of the Minister of the Environment from (2014).

In this study, the Rhodotorula yeast showed the ability to biosynthesize intracellular lipids under control and experimental conditions. Reducing the temperature of cultivation to $20^{\circ} \mathrm{C}$ intensified the biosynthesis of lipids by $R$. glutinis yeast (Table 1 ). After $120 \mathrm{~h}$ of cultivation at $20^{\circ} \mathrm{C}$, the lipid content produced by $R$. glutinis increased by $67 \%\left(17.4 \mathrm{~g} / 100 \mathrm{~g}_{\text {d.w. }}\right)$ compared to the control culture $\left(10.4 \mathrm{~g} / 100 \mathrm{~g}_{\text {d.w. }}\right)$. The biomass of $R$. mucilaginosa obtained after cultivation in control and experimental conditions (osmotic stress, oxidative stress, and under white light irradiation) showed similar yield in of intracellular lipids, which after the $120 \mathrm{~h}$ ranged from 10.9 to $13.4 \mathrm{~g} / 100 \mathrm{~g}$ d.w. . Similar to $R$. glutinis, low temperature $\left(20^{\circ} \mathrm{C}\right)$ intensified the process of lipid biosynthesis by R.mucilaginosa and its content 
Table 1 Parameters characterizing the biosynthesis of lipids by Rhodotorula yeast strains after $120 \mathrm{~h}$ of cultivation in control and experimental conditions

\begin{tabular}{lllll}
\hline Culture conditions & $\begin{array}{l}\text { Total lipid content in yeast } \\
\text { biomass }\left(\mathrm{g} / 100 \mathrm{~g}_{\mathrm{d} . w .}\right)\end{array}$ & $\begin{array}{l}\mathrm{Y}_{\mathrm{L}} \\
(\mathrm{g} / \mathrm{L})\end{array}$ & $\begin{array}{l}\mathrm{Q}_{\mathrm{L}} \\
(\mathrm{g} / \mathrm{L} / \mathrm{h})\end{array}$ & $\begin{array}{l}\mathrm{Y}_{\mathrm{L} / \mathrm{CS}} \\
(\mathrm{g} / \mathrm{g})\end{array}$ \\
\hline Rhodotorula glutinis & & & & \\
Control & $10.4 \pm 0.4^{\mathrm{b}}$ & $2.11 \pm 0.07^{\mathrm{b}}$ & $0.018 \pm 0.001^{\mathrm{b}}$ & $0.057 \pm 0.002^{\mathrm{b}}$ \\
$+5 \% \mathrm{NaCl}$ & $12.4 \pm 1.5^{\mathrm{b}}$ & $1.40 \pm 0.30^{\mathrm{c}}$ & $0.012 \pm 0.002^{\mathrm{c}}$ & $0.111 \pm 0.032^{\mathrm{a}}$ \\
$+5 \mathrm{mM} \mathrm{H} \mathrm{O}_{2}$ & $10.9 \pm 0.6^{\mathrm{b}}$ & $2.25 \pm 0.21^{\mathrm{b}}$ & $0.019 \pm 0.002^{\mathrm{b}}$ & $0.060 \pm 0.005^{\mathrm{b}}$ \\
Culture at 20 ${ }^{\circ} \mathrm{C}$ & $17.4 \pm 1.4^{\mathrm{a}}$ & $3.82 \pm 0.32^{\mathrm{a}}$ & $0.032 \pm 0.003^{\mathrm{a}}$ & $0.103 \pm 0.009^{\mathrm{a}}$ \\
White light irradiation & $10.7 \pm 0.4^{\mathrm{b}}$ & $2.26 \pm 0.14^{\mathrm{b}}$ & $0.019 \pm 0.001^{\mathrm{b}}$ & $0.062 \pm 0.004^{\mathrm{b}}$ \\
Rhodotorula mucilaginosa & & & & \\
Control & $12.4 \pm 1.5^{\mathrm{b}}$ & $2.71 \pm 0.30^{\mathrm{b}}$ & $0.023 \pm 0.003^{\mathrm{b}}$ & $0.075 \pm 0.008^{\mathrm{b}}$ \\
$+5 \% \mathrm{NaCl}$ & $13.3 \pm 1.9^{\mathrm{b}}$ & $2.87 \pm 0.38^{\mathrm{b}}$ & $0.024 \pm 0.003^{\mathrm{b}}$ & $0.080 \pm 0.011^{\mathrm{ab}}$ \\
+5 mM $\mathrm{H}_{2} \mathrm{O}_{2}$ & $12.5 \pm 0.7^{\mathrm{b}}$ & $2.71 \pm 0.06^{\mathrm{b}}$ & $0.023 \pm 0.001^{\mathrm{b}}$ & $0.073 \pm 0.003^{\mathrm{b}}$ \\
Culture at 20 ${ }^{\circ} \mathrm{C}$ & $16.3 \pm 1.4^{\mathrm{a}}$ & $3.49 \pm 0.24^{\mathrm{a}}$ & $0.029 \pm 0.002^{\mathrm{a}}$ & $0.095 \pm 0.011^{\mathrm{a}}$ \\
White light irradiation & $11.0 \pm 0.9^{\mathrm{b}}$ & $2.34 \pm 0.21^{\mathrm{c}}$ & $0.020 \pm 0.002^{\mathrm{c}}$ & $0.064 \pm 0.004^{\mathrm{c}}$ \\
Rhodotorula gracilis & & & & \\
Control & $15.5 \pm 1.2^{\mathrm{b}}$ & $3.30 \pm 0.30^{\mathrm{b}}$ & $0.027 \pm 0.002^{\mathrm{b}}$ & $0.089 \pm 0.010^{\mathrm{b}}$ \\
$+5 \%$ NaCl & $14.4 \pm 1.8^{\mathrm{b}}$ & $2.73 \pm 0.37^{\mathrm{c}}$ & $0.023 \pm 0.003^{\mathrm{b}}$ & $0.084 \pm 0.008^{\mathrm{b}}$ \\
+5 mM $\mathrm{H}_{2} \mathrm{O}_{2}$ & $14.3 \pm 0.8^{\mathrm{b}}$ & $2.17 \pm 0.05^{\mathrm{d}}$ & $0.018 \pm 0.000^{\mathrm{c}}$ & $0.084 \pm 0.004^{\mathrm{b}}$ \\
Culture at $20^{\circ} \mathrm{C}$ & $21.1 \pm 1.11^{\mathrm{a}}$ & $4.52 \pm 0.36^{\mathrm{a}}$ & $0.038 \pm 0.003^{\mathrm{a}}$ & $0.124 \pm 0.007^{\mathrm{a}}$ \\
White light irradiation & $14.8 \pm 2.0^{\mathrm{b}}$ & $3.05 \pm 0.55^{\mathrm{bc}}$ & $0.025 \pm 0.005^{\mathrm{b}}$ & $0.082 \pm 0.013^{\mathrm{b}}$ \\
\hline
\end{tabular}

$\mathrm{Y}_{\mathrm{L}}$ - volumetric yield of lipid (grams per liter of medium); $\mathrm{Q}_{\mathrm{L}}$-volumetric lipid productivity (grams per liter of medium per hour); $\mathrm{Y}_{\mathrm{L} / \mathrm{CS}}$-yield of lipids per consumed carbon source (gram of lipid per gram of consumed carbon sources); $\mathrm{a}, \mathrm{b}, \mathrm{c} .$. -indexes mean homogeneous groups determined by Tukey's test at the level of significance 0.05 $\left(16.3 \mathrm{~g} / 100 \mathrm{~g}_{\text {d.w. }}\right)$ increased by $31 \%$ compared to the control conditions (12.4 g/100 $\left.\mathrm{g}_{\text {d.w. }}\right)$. Among all the studied strains, $R$. gracilis synthesized the greatest amounts of intracellular lipids. After $120 \mathrm{~h}$ of cultivation at low temperature, the total content of cellular lipid was $21.1 \mathrm{~g} / 100 \mathrm{~g}_{\mathrm{d} . \mathrm{w}}$; therefore, under these tested conditions, $R$. gracilis yeast fulfilled the criterion of being in the category of oleaginous yeast. It synthesized $36 \%$ higher amounts of lipids than that of the control culture $\left(15.5 \mathrm{~g} / 100 \mathrm{~g}_{\mathrm{d} . \mathrm{w}}\right)$. In the remaining experimental conditions (under osmotic stress, oxidative stress, and white light irradiation), the lipid content obtained after $120 \mathrm{~h}$ of cultivation was similar $\left(14.3-14.9 \mathrm{~g} / 100 \mathrm{~g}_{\mathrm{d} . w .}\right)$ to that obtained under control conditions. The highest value of the volumetric yield of lipid biosynthesis $(4.52 \mathrm{~g} / \mathrm{L})$ and productivity $(0.038 \mathrm{~g} / \mathrm{L} / \mathrm{h})$ was obtained after $120 \mathrm{~h}$ of $R$. gracilis yeast cultivation at $20{ }^{\circ} \mathrm{C}$. For $R$. glutinis and $R$. mucilaginosa yeasts values of $\mathrm{Y}_{\mathrm{L}}$ and $\mathrm{Q}_{\mathrm{L}}$ also were the highest and were respectively $3.82 \mathrm{~g} / \mathrm{L}$ and $0.032 \mathrm{~g} / \mathrm{L} / \mathrm{h}$ for $R$. glutinis and $3.49 \mathrm{~g} / \mathrm{L}$ and $0.029 \mathrm{~g} / \mathrm{L} / \mathrm{h}$ for $R$. mucilaginosa. At $20^{\circ} \mathrm{C}$, the highest yield of lipids per consumed carbon source was obtained for $R$. gracilis yeast $(0.124 \mathrm{~g} / \mathrm{g})$, which confirms the suitability of $R$. gracilis strain for the synthesis of lipids from waste materials.

Depending on the culture conditions, fatty acid composition was dominated by palmitic, stearic, oleic, and linoleic, and their percentages were dependent on the culture conditions (Figs. 1, 2, 3). The yeast synthesized oleic acid

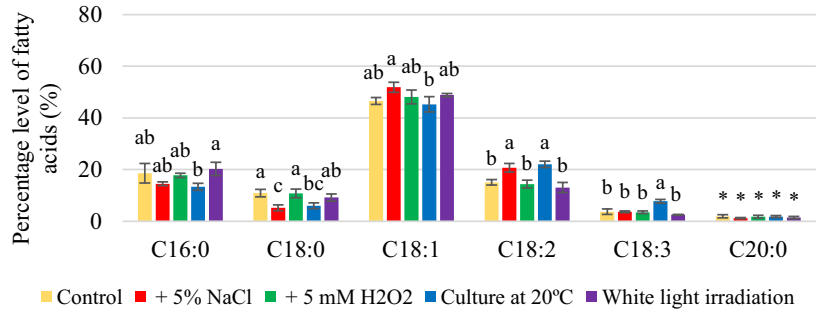

Fig. 1 Percentage levels of fatty acids synthesized by Rhodotorula glutinis yeast after $120 \mathrm{~h}$ of cultivation in control and experimental conditions $(\mathrm{a}, \mathrm{b}, \mathrm{c} .$. - -indexes mean homogeneous groups, *no significant differences, Tukey's test, $\alpha=0.05$ )

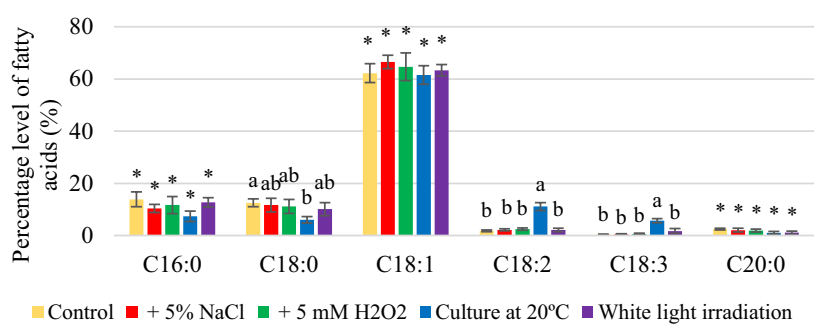

Fig. 2 Percentage levels of fatty acids synthesized by Rhodotorula mucilaginosa yeast after $120 \mathrm{~h}$ of cultivation in control and experimental conditions ( $a, b, c .$. -indexes mean homogeneous groups, *no significant differences, Tukey's test, $\alpha=0.05$ ) 


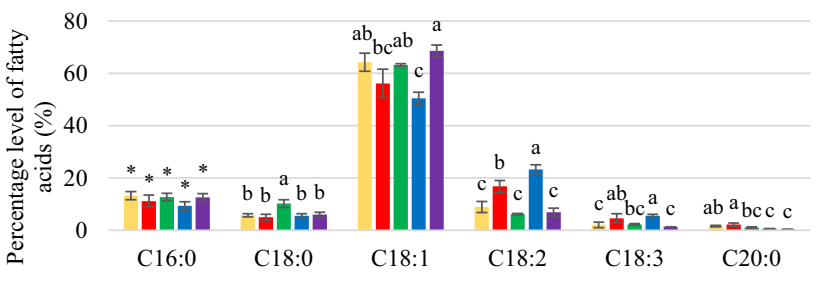

$\square$ Control $\square+5 \% \mathrm{NaCl} \square+5 \mathrm{mM} \mathrm{H} 2 \mathrm{O} 2 \square$ Culture at $20^{\circ} \mathrm{C} \backsim$ White light irradiation

Fig. 3 Percentage levels of fatty acids synthesized by Rhodotorula gracilis yeast after $120 \mathrm{~h}$ of cultivation in control and experimental conditions ( $a, b, c .$. -indexes mean homogeneous groups, *no significant differences, Tukey's test, $\alpha=0.05$ )

(45.3-68.5\%). Reducing the temperature of growing conditions from 28 to $20{ }^{\circ} \mathrm{C}$ significantly increased the content of unsaturated fatty acids (Figs. S4, S5, S6), especially linoleic and linolenic acids. The percentage of linolenic acid was respectively 22.0 and $23.2 \%$ obtained for $R$. glutinis and $R$. gracilis yeasts. However, $R$. mucilaginosa synthesized linolenic acid in a significantly less quantity than the other two strains (11.1\%), but it was six-fold greater than that of the control culture (1.8\%). The highest amount of PUFA (30.4\%) was found in lipids extracted from $R$. gracilis yeast biomass after cultivation at $20^{\circ} \mathrm{C}$, which was 2.5 times more than that of the control culture (Figure S6). This was due to the presence of increased amounts of linoleic and linolenic acids. $R$. glutinis yeast also efficiently synthesized linoleic and linolenic acids at $20^{\circ} \mathrm{C}$, and the amount of PUFA was determined at around $29.7 \%$ (Fig. S4). For R. glutinis and $R$. gracilis yeast strains, a significant increase in the amount of linoleic and linolenic acids was also found in the medium representing osmotic stress; however, the quantity was lower than that of cultivation at $20^{\circ} \mathrm{C}$. Thus, the yeast biomass of $R$. glutinis and $R$. gracilis strains obtained after cultivation at $20^{\circ} \mathrm{C}$ in the media containing potato wastewater supplemented with $3 \%$ glycerol can be recommended as an additive to livestock feed supplement containing unsaturated fatty acids, especially oleic, linoleic, and linolenic acid.

The amount of carotenoids synthesized by yeast strains was determined under the conditions of exogenous stress (Table 2). After $120 \mathrm{~h}$ of cultivation under osmotic stress, oxidative stress, and white light irradiation, the amount of carotenoid biosynthesis in the yeast biomass of $R$. $g l u$ tinis was similar in both control and experimental conditions (ranging from 220.7 to $249.1 \mu \mathrm{g} / \mathrm{g}_{\text {d.w. }}$ ). Carotenoid biosynthesis was found to be increased after cultivation at $20^{\circ} \mathrm{C}\left(280.3 \mu \mathrm{g} / \mathrm{g}_{\text {d.w. }}\right)$. The same relationship was found for $R$. mucilaginosa yeast. After $120 \mathrm{~h}$ of cultivation at $20^{\circ} \mathrm{C}$, $R$. mucilaginosa synthesized $46 \%$ more total carotenoids $\left(150.7 \mu \mathrm{g} / \mathrm{g}_{\text {d.w. }}\right)$ than that of the control culture $(103.0 \mu \mathrm{g} /$ $\mathrm{g}_{\text {d.w. }}$ ). The process of carotenoid biosynthesis by $R$. gracilis yeast was increased under low temperatures $\left(20^{\circ} \mathrm{C}\right)$ and white light irradiation. After $120 \mathrm{~h}$ of incubation, $R$. gracilis
Table 2 Parameters characterizing the biosynthesis of carotenoids by Rhodotorula yeast after $120 \mathrm{~h}$ of cultivation in control and experimental conditions

\begin{tabular}{lllll}
\hline Culture conditions & $\begin{array}{l}\text { Total carotenoid content } \\
\text { in biomass }\left(\mu \mathrm{g} / \mathrm{g}_{\text {d.w. }}\right)\end{array}$ & $\begin{array}{l}\mathrm{Y}_{\mathrm{CAR}} \\
(\mathrm{mg} / \mathrm{L})\end{array}$ & $\begin{array}{l}\mathrm{Q}_{\mathrm{CAR}} \\
(\mathrm{mg} / \mathrm{L} / \mathrm{h})\end{array}$ & $\begin{array}{l}\mathrm{Y}_{\mathrm{CAR} / \mathrm{CS}} \\
(\mathrm{mg} / \mathrm{g})\end{array}$ \\
\hline Rhodotorula glutinis & & & & \\
Control & $235.6 \pm 18.9^{\mathrm{b}}$ & $4.78 \pm 0.48^{\mathrm{b}}$ & $0.040 \pm 0.004^{\mathrm{b}}$ & $0.130 \pm 0.012^{\mathrm{c}}$ \\
$+5 \% \mathrm{NaCl}$ & $249.1 \pm 12.1^{\mathrm{ab}}$ & $2.79 \pm 0.26^{\mathrm{c}}$ & $0.023 \pm 0.002^{\mathrm{c}}$ & $0.220 \pm 0.038^{\mathrm{a}}$ \\
$+5 \mathrm{mM} \mathrm{H} \mathrm{O}_{2}$ & $228.2 \pm 16.3^{\mathrm{b}}$ & $4.69 \pm 0.15^{\mathrm{b}}$ & $0.039 \pm 0.001^{\mathrm{b}}$ & $0.126 \pm 0.005^{\mathrm{c}}$ \\
Culture at 20 ${ }^{\circ} \mathrm{C}$ & $280.3 \pm 16.0^{\mathrm{a}}$ & $6.16 \pm 0.50^{\mathrm{a}}$ & $0.051 \pm 0.004^{\mathrm{a}}$ & $0.167 \pm 0.014^{\mathrm{b}}$ \\
White light irradiation & $220.7 \pm 14.7^{\mathrm{b}}$ & $4.67 \pm 0.43^{\mathrm{b}}$ & $0.039 \pm 0.004^{\mathrm{b}}$ & $0.129 \pm 0.012^{\mathrm{c}}$ \\
Rhodotorula mucilaginosa & & & & \\
Control & $103.0 \pm 10.5^{\mathrm{b}}$ & $2.26 \pm 0.26^{\mathrm{b}}$ & $0.019 \pm 0.002^{\mathrm{b}}$ & $0.062 \pm 0.006^{\mathrm{b}}$ \\
$+5 \% \mathrm{NaCl}$ & $111.2 \pm 9.3^{\mathrm{b}}$ & $2.40 \pm 0.15^{\mathrm{b}}$ & $0.020 \pm 0.001^{\mathrm{b}}$ & $0.067 \pm 0.006^{\mathrm{b}}$ \\
$+5 \mathrm{mM} \mathrm{H}_{2} \mathrm{O}_{2}$ & $115.5 \pm 12.9^{\mathrm{b}}$ & $2.50 \pm 0.35^{\mathrm{b}}$ & $0.021 \pm 0.003^{\mathrm{b}}$ & $0.068 \pm 0.010^{\mathrm{b}}$ \\
Culture at 20 ${ }^{\circ} \mathrm{C}$ & $150.7 \pm 11.8^{\mathrm{a}}$ & $3.23 \pm 0.29^{\mathrm{a}}$ & $0.027 \pm 0.002^{\mathrm{a}}$ & $0.088 \pm 0.009^{\mathrm{a}}$ \\
White light irradiation & $108.4 \pm 10.8^{\mathrm{b}}$ & $2.32 \pm 0.27^{\mathrm{b}}$ & $0.019 \pm 0.002^{\mathrm{b}}$ & $0.063 \pm 0.008^{\mathrm{b}}$ \\
Rhodotorula gracilis & & & & \\
Control & $229.9 \pm 18.7^{\mathrm{c}}$ & $4.89 \pm 0.49^{\mathrm{cd}}$ & $0.041 \pm 0.004^{\mathrm{c}}$ & $0.132 \pm 0.018^{\mathrm{c}}$ \\
$+5 \% \mathrm{NaCl}$ & $211.5 \pm 15.7^{\mathrm{c}}$ & $4.00 \pm 0.24^{\mathrm{d}}$ & $0.033 \pm 0.002^{\mathrm{d}}$ & $0.123 \pm 0.011^{\mathrm{c}}$ \\
+5 mM $\mathrm{H}_{2} \mathrm{O}_{2}$ & $277.1 \pm 17.1^{\mathrm{b}}$ & $4.22 \pm 0.53^{\mathrm{d}}$ & $0.035 \pm 0.004^{\mathrm{d}}$ & $0.163 \pm 0.013^{\mathrm{b}}$ \\
Culture at 20 ${ }^{\circ} \mathrm{C}$ & $360.4 \pm 11.1^{\mathrm{a}}$ & $7.72 \pm 0.28^{\mathrm{a}}$ & $0.064 \pm 0.002^{\mathrm{a}}$ & $0.212 \pm 0.006^{\mathrm{a}}$ \\
White light irradiation & $307.2 \pm 7.9^{\mathrm{b}}$ & $6.29 \pm 0.36^{\mathrm{b}}$ & $0.052 \pm 0.003^{\mathrm{b}}$ & $0.170 \pm 0.007^{\mathrm{b}}$ \\
\hline
\end{tabular}

$\mathrm{Y}_{\mathrm{CAR}}$ - volumetric yield of carotenoids (milligrams per liter of medium); $\mathrm{Q}_{\mathrm{CAR}}$-volumetric carotenoids productivity (milligrams per liter of medium per hour); $\mathrm{Y}_{\mathrm{CAR} / \mathrm{CS}}$-yield of carotenoids per consumed carbon source (milligram of carotenoids per gram of consumed carbon sources); a, b, c...-indexes mean homogeneous groups determined by Tukey's test at the level of significance 0.05 
yeast synthesized 57\% (360.4 $\left.\mu \mathrm{g} / \mathrm{g}_{\text {d.w. }}\right)$ and 34\% (307.2 $\mu \mathrm{g} /$ $\left.\mathrm{g}_{\text {d.w. }}\right)$ more carotenoids than that of control culture $(229.9 \mu \mathrm{g} /$ $\mathrm{g}_{\text {d.w. }}$ ). According to our results, low temperature most effectively stimulated the biosynthesis of carotenoid by Rhodotorula yeasts. After taking the yield of cellular biomass into account, the highest volumetric yield of carotenoid biosynthesis $(7.72 \mathrm{mg} / \mathrm{L})$ was found after cultivation of $R$. gracilis at $20^{\circ} \mathrm{C}$, which was around $57 \%$ increase in the volumetric yield). Most of the carbon was utilized for the biosynthesis of carotenoids by $R$. gracilis during cultivation at $20^{\circ} \mathrm{C}$. The highest yield of carotenoids per consumed carbon source was $0.212 \mathrm{mg} / \mathrm{g}$, and the strains utilized more than $60 \%$ of the carbon for the biosynthesis of carotenoids than that of control conditions $(0.132 \mathrm{mg} / \mathrm{g})$.

The individual fractions of carotenoid depended both on the yeast strain and on the culture conditions (Table 3 ). Osmotic stress stimulated the biosynthesis of $\beta$-carotene by $R$. glutinis yeast. After $120 \mathrm{~h}$ of cultivation, the amount of $\beta$-carotene was $50.3 \%$ of the total carotenoid fraction, whereas in the control culture, it was $10 \%$ lower than the experimental culture. The same pattern was observed for the culture at $20^{\circ} \mathrm{C}$, and the proportion of $\beta$-carotene synthesized by $R$. glutinis under these conditions was significantly higher (62.7\%) than that of the other strains. The presence of oxidative stress was found to stimulate the biosynthesis of torulene (76.8\%). Irradiation with white light stimulated

Table 3 The percentage levels of $\beta$-carotene, torulene, and torularhodin in carotenoid fractions extracted from Rhodotorula yeast biomass after $120 \mathrm{~h}$ of cultivation

\begin{tabular}{lcll}
\hline Culture conditions & $\beta$-carotene & Torulene & Torularhodin \\
\hline Rhodotorula glutinis & & & \\
Control & $38.4 \pm 1.8^{\mathrm{c}}$ & $48.9 \pm 7.8^{\mathrm{b}}$ & $7.8 \pm 2.7^{\mathrm{b}}$ \\
$+5 \% \mathrm{NaCl}$ & $50.3 \pm 3.4^{\mathrm{b}}$ & $44.0 \pm 3.7^{\mathrm{b}}$ & $3.4 \pm 1.1^{\mathrm{c}}$ \\
$+5 \mathrm{mM} \mathrm{H}_{2} \mathrm{O}_{2}$ & $20.4 \pm 3.8^{\mathrm{d}}$ & $76.8 \pm 3.5^{\mathrm{a}}$ & $1.4 \pm 0.7^{\mathrm{d}}$ \\
Culture at $20^{\circ} \mathrm{C}$ & $62.7 \pm 2.2^{\mathrm{a}}$ & $33.6 \pm 2.4^{\mathrm{c}}$ & $0.4 \pm 0.3^{\mathrm{e}}$ \\
White light irradiation & $40.7 \pm 1.8^{\mathrm{c}}$ & $35.4 \pm 2.2^{\mathrm{c}}$ & $21.5 \pm 1.6^{\mathrm{a}}$ \\
Rhodotorula mucilaginosa & & & \\
Control & $18.2 \pm 1.7^{\mathrm{b}}$ & $74.8 \pm 0.7^{\mathrm{b}}$ & $3.8 \pm 1.2^{\mathrm{b}}$ \\
$+5 \% \mathrm{NaCl}$ & $38.8 \pm 1.7^{\mathrm{a}}$ & $56.4 \pm 3.4^{\mathrm{d}}$ & $0.8 \pm 0.4^{\mathrm{cd}}$ \\
$+5 \mathrm{mM} \mathrm{H}_{2} \mathrm{O}_{2}$ & $15.1 \pm 3.0^{\mathrm{bc}}$ & $82.2 \pm 3.6^{\mathrm{a}}$ & $1.6 \pm 0.9^{\mathrm{c}}$ \\
Culture at $20{ }^{\circ} \mathrm{C}$ & $45.4 \pm 5.9^{\mathrm{a}}$ & $53.1 \pm 6.0^{\mathrm{d}}$ & $0.5 \pm 0.2^{\mathrm{d}}$ \\
White light irradiation & $12.9 \pm 2.0^{\mathrm{c}}$ & $67.8 \pm 2.2^{\mathrm{c}}$ & $16.4 \pm 1.0^{\mathrm{a}}$ \\
Rhodotorula gracilis & & & \\
Control & $59.5 \pm 3.0^{\mathrm{c}}$ & $38.8 \pm 2.3^{\mathrm{c}}$ & $\mathrm{nd}$ \\
$+5 \% \mathrm{NaCl}$ & $75.5 \pm 2.5^{\mathrm{a}}$ & $22.5 \pm 2.1^{\mathrm{e}}$ & $\mathrm{nd}$ \\
$+5 \mathrm{mM} \mathrm{H}_{2} \mathrm{O}_{2}$ & $32.8 \pm 2.7^{\mathrm{d}}$ & $65.6 \pm 3.0^{\mathrm{b}}$ & $\mathrm{nd}$ \\
Culture at $20{ }^{\circ} \mathrm{C}$ & $68.2 \pm 2.9^{\mathrm{b}}$ & $30.7 \pm 2.5^{\mathrm{d}}$ & $\mathrm{nd}$ \\
White light irradiation & $22.0 \pm 2.0^{\mathrm{e}}$ & $76.1 \pm 2.0^{\mathrm{a}}$ & $\mathrm{nd}$ \\
\hline
\end{tabular}

$N d$ not detected

$\mathrm{a}, \mathrm{b}, \mathrm{c} . .$. -indexes mean homogeneous groups determined by Tukey's test at the level of significance 0.05 the production of torularhodin $(21.5 \%)$. In the control and experimental conditions, the $R$. mucilaginosa yeast primarily synthesized torulene and $\beta$-carotene. The percentage of torulene was the highest (82.2\%) after cultivation in of yeast cells under oxidative stress. Similar to $R$. glutinis yeast, there was a significant increase (more than 50\%) in the synthesis of $\beta$-carotene by $R$. mucilaginosa yeast under osmotic stress and at $20^{\circ} \mathrm{C}$. Irradiation with white light increased the production of torularhodin by $R$. mucilaginosa. In comparison to the control culture (3.8\%), R. mucilaginosa grown under irradiation showed a four-fold (16.4\%) increased the production of torularhodin. Irradiation of $R$. gracilis culture with white light resulted in a significant increase in the percentage of torulene $(76.1 \%)$. Similar to the other two strains, $R$. gracilis yeast synthesized torulene in greater quantities under oxidative stress, whereas osmotic stress and low temperature increased the production of $\beta$-carotene.

\section{Discussion}

According to the results of this study, the applied exogenous stress factors stimulated the biosynthesis of various compounds by the yeast in the presence of agro-industrial waste. The low temperature increased the amount of biosynthesis and accumulation of intracellular lipids. It is generally recognized that the optimum temperature for the growth and biosynthesis of lipids by oleaginous yeasts is $30{ }^{\circ} \mathrm{C}$ (Mohammed et al. 2018); however, some strains synthesize lipids more efficiently at lower temperatures (Zhang et al. 2014), which may result from the higher expression of genes coding for the production of specific desaturases (He et al. 2015). Modification of the composition of lipids is a natural mechanism of adaptation of microorganisms to low temperatures, ensuring the fluidity of plasma membranes, which determines the proper course of cellular transport processes (Suutari et al. 1990; He et al. 2015).

Based on the results of this study, low temperature $\left(20^{\circ} \mathrm{C}\right)$ effectively increased the biosynthesis of carotenoids by the yeast strains. A similar relationship was also observed by Martin et al. (1993), Vijayalakshmi et al. (2001), Bhosale and Gadre (2002), and Nasrabadi and Razavi (Nasrabadi and Razavi 2011). Vijayalakshmi et al. (2001) decreased the incubation temperature of $R$. gracilis yeast from 32 to $24^{\circ} \mathrm{C}$ which resulted in an increase in the content of carotenoids from 148 to $622 \mu \mathrm{g} / 100 \mathrm{~g}_{\text {d.w. }}$. The incubation temperature influences the process of carotenogenesis by regulating the concentration and activity of enzymes that catalyze the reactions taking place in this pathway (Hayman et al. 1974; Frengova et al. 1995); however, its effect is dependent on the strain, composition of the medium, and other environmental parameters. 
The applied exogenous stress factors significantly affected the profile of carotenoids synthesized by the yeast strains, such as torularhodin, torulene, and $\beta$-carotene. The biosynthesis of torularhodin was stimulated after the irradiation of yeast cells with white light. These results agree with those reported by Sakaki et al. (2001). They found that increased biosynthesis of torularhodin is an important protective mechanism of yeast cells against radiation damage because it has the ability to neutralize free radicals, especially singlet oxygen. Although singlet oxygen molecules and other free radicals are mainly generated during exposure to UV radiation (Moliné et al. 2009), it cannot be ruled out that illumination of cells in the visible range increased the production of free radicals in yeast cells.

In this study, the addition of hydrogen peroxide to the culture medium led to the increased biosynthesis of torulene by all the yeast strains. Irazusta et al. (2013) also reported that oxidative stress $\left(5 \mathrm{mM} \mathrm{H}_{2} \mathrm{O}_{2}\right)$ stimulated the biosynthesis of torulene by $R$. mucilaginosa $\mathrm{RCL}-11$ yeast; the fraction of torulene in the total pool of carotenoids synthesized was obtained from 21.3 to $45.6 \%$. Thus, it is safe to assume that under in vivo conditions, torulene exhibits higher activity against reactive oxygen species than that of $\beta$-carotene and torularhodin ( $\mathrm{Li}$ et al. 2017). The ability to neutralize the harmful effects of hydrogen peroxide by torulene and torularhodin recently has been confirmed by Du et al. (2017).

Low temperature and osmotic stress stimulated the biosynthesis of $\beta$-carotene by Rhodotorula yeast. This phenomenon was also observed by Simpson et al. (1964), Frengova et al. (1995), Bhosale and Gadre (2002), and Cheng and Yang (2016). Bhosale and Gadre (2002) found that decreasing the temperature of cultivation of $R$. glutinis yeast from 32 to $20{ }^{\circ} \mathrm{C}$, increased the production of $\beta$-carotene from 66 to $92 \%$, as well increased the total carotenoids content from 125.0 to $250 \mathrm{mg} / \mathrm{L}$. The temperature of the culture medium during cultivation of yeast biomass affects the level of enzymes involved in the biosynthetic pathway of these compounds. At low temperatures, enzymes involved in the conversion of $\gamma$-carotene to torulene are less active, as a result of which $\gamma$-carotene is converted mainly to $\beta$-carotene [Simpson et al. 1964; Bhosale 2004].

In this study, osmotic stress stimulated the biosynthesis of $\beta$-carotene by all the yeast strains. This result was also obtained by Bhosale and Gadre (2001) during cultivation of $R$. glutinis no. 32 yeast in a medium based on seawater, which contained $23.1 \mathrm{~g} / \mathrm{L}$ of sodium chloride. Under these conditions, a two-fold increase in the content of $\beta$-carotene and a simultaneous reduction (twofold) in the yield of torulene was observed in relation to the control culture medium prepared with distilled water. According to the authors, there was higher activity of lycopene cyclase, which was stimulated by the presence of micronutrients in seawater.
The analysis of our own results and those reported by other authors indicated that the tested stress factors can effectively enhance the biosynthesis of carotenoids and lipids by the red yeast. The degree of intensification and trend of changes in the profile of carotenoids and fatty acids depended on the type of stress factor used, the strain of red yeast used, the composition of the basic culture medium, and the culture conditions. The main similarities between the our results and those reported by other authors relate to: a) an increase in the pool of unsaturated fatty acids during culturing at low temperature; b) an increase in the content of carotenoids in the yeast biomass after cultivation at a low temperature, and c) changes in the levels of individual carotenoid fractions ( $\beta$-carotene, torulene, torularhodin) depending on the type of stress factor applied. A significant difference was observed with regard to the optimum temperature required for the lipid biosynthesis. In this study, a relevant increase in lipid content was demonstrated after cultivation at $20^{\circ} \mathrm{C}$, while other studies showed that the highest content of these compounds in biomass was obtained for cultures incubated at a temperature of about $30^{\circ} \mathrm{C}$. The results show that the optimal culture temperature should be determined for each yeast strain, which in turn depends on the culture medium used. The composition of the experimental medium could also have contributed to the obtained different results. It is probable that lipid biosynthesis would occur more efficiently at higher temperatures when a different media is used. It is also possible that the type of medium used had a strong impact on the degree of escalation of lipid and carotenoid biosynthesis in the other conditions studied; however, in order to verify this hypothesis, tests should be carried out using at least several different types of basal media for comparison.

\section{Conclusion}

This study shows the possibility of modifying the content and profile of lipids and carotenoids that are synthesized by yeast belonging to the genus Rhodotorula by modifying the culture conditions (e.g., under osmotic and oxidative stress, irradiation with white light, and by lowering the temperature). Among the tested exogenous stress factors, the biosynthesis of intracellular lipids, as well as carotenoids, was most effective at $20^{\circ} \mathrm{C}$. At $20^{\circ} \mathrm{C}, R$. gracilis synthesized $21.1 \mathrm{~g} / 100 \mathrm{~g}_{\text {d.w. }}$ lipids, which also significantly increased the content of unsaturated fatty acids in yeast lipids, especially linoleic and linolenic acids. In addition, low temperature stimulated the biosynthesis of carotenoids by all the yeast strains, and their highest content $\left(360.4 \mu \mathrm{g} / \mathrm{g}_{\text {d.w. }}\right)$ was recorded for $R$. gracilis yeast after $120 \mathrm{f}$ of cultivation. The applied stress factors significantly affected the profile of carotenoids synthesized by the yeasts. Furthermore, we 
found a significant increase in the proportion of $\beta$-carotene in the total pool of synthesized carotenoids at low temperatures and under osmotic stress. Under oxidative stress, the yeast strains synthesized more torulene than that of the control conditions. In addition, irradiation stimulated the biosynthesis of torularhodin ( $R$. glutinis and $R$. mucilaginosa) and torulene ( $R$. gracilis), which shows that these chemicals are an important protective factor of cells against the oxidative stress.

Acknowledgements The authors thank Translmed (Cedar Hill, TX, USA), a proofreading and copyediting company, for helping in copyediting this manuscript.

Funding This study was supported by the grant from the Polish Ministry of Science and Higher Education for the implementation of the project for young scientists (Grant No. 505-10-092800-P00211-99).

\section{Compliance with ethical standards}

Conflict of interest The authors declare that they have no conflicts of interest in this study.

Research involving human and/or animal participants This study does not involve research on human participants or animals.

Open Access This article is distributed under the terms of the Creative Commons Attribution 4.0 International License (http://creativecommons.org/licenses/by/4.0/), which permits unrestricted use, distribution, and reproduction in any medium, provided you give appropriate credit to the original author(s) and the source, provide a link to the Creative Commons license, and indicate if changes were made.

\section{References}

Amaretti A, Raimondi S, Sala M, Roncaglia L, De Lucia M, Leonardi A, Rossi M (2010) Single cell oils of the cold-adapted oleaginous yeast Rhodotorula glacialis DBVPG 4785. Microb Cell Fact 9:73. https://doi.org/10.1186/1475-2859-9-73

Bhosale PB (2004) Environmental and cultural stimulants in the production of carotenoids from microorganisms. Appl Microbiol Biotechnol 63(4):351-361. https://doi.org/10.1007/s0025 3-003-1441-1

Bhosale PB, Gadre RV (2001) Production of $\beta$-carotene from Rhodotorula glutinis mutant in sea water medium. Bioresour Technol 76(1):53-55. https://doi.org/10.1016/S0960-8524(00)00075-4

Bhosale P, Gadre RV (2002) Manipulation of temperature and illumination conditions for enhanced $\beta$-carotene production by mutant 32 of Rhodotorula glutinis. Lett Appl Microbiol 34(5):349-353. https://doi.org/10.1046/j.1472-765X.2002.01095.x

Cheng YT, Yang CF (2016) Using strain Rhodotorula mucilaginosa to produce carotenoids using food wastes. J Taiwan Inst Chem E 61:270-275. https://doi.org/10.1016/j.jtice.2015.12.027

Cutzu R, Coi A, Rosso F, Bardi L, Ciani M, Budroni M, Zara G, Zara S, Mannazzu I (2013) From crude glycerol to carotenoids by using a Rhodotorula glutinis mutant. World J Microbiol Biotechnol 29(6):1009-1017. https://doi.org/10.1007/s11274-013-1264-X

Du C, Guo Y, Cheng Y, Han M, Zhang W, Qian H (2017) Torulene and torularhodin, protects human prostate stromal cells from hydrogen peroxide-induced oxidative stress damage through the regulation of Bcl-2/Bax mediated apoptosis. Free Radic Res 51(2):113-123. https://doi.org/10.1080/10715762.2017.1285024

Fell JW, Statzell-Tallman A (1998) 'Rhodotorula' Harison. W: The yeast, a taxonomic study (red. Kurtzman CP, Fell JW). Elsevier, Amsterdam, pp 800-827

Frengova GI, Beshkova DM (2009) Carotenoids from Rhodotorula and Phaffia: yeasts of biotechnological importance. J Ind Microbiol Biotechnol 36(2):163-180. https://doi.org/10.1007/s1029 5-008-0492-9

Frengova GI, Simova ED, Beshkova DM (1995) Effect of temperature changes on the production of yeast pigments co-cultivated with lacto-acid bacteria in whey ultrafiltrate. Biotechnol Lett 17:10011006. https://doi.org/10.1007/BF00127443

Hayman EP, Yokoyama H, Chichester CO, Simpson KL (1974) Carotenoid biosynthesis in Rhodotorula glutinis. J Bacteriol 120(3):1339-1343

He J, Yang Z, Hu B, Ji X, Wei Y, Lin L, Zhang Q (2015) Correlation of polyunsaturated fatty acids with the cold adaptation of Rhodotorula glutinis. Yeast 32(11):683-690. https://doi.org/10.1002/ yea.3095

Irazusta V, Nieto-Penalver CG, Cabral ME, Amoroso MJ, de Figueroa LIC (2013) Relationship among carotenoid production, copper bioremediation and oxidative stress in Rhodotorula mucilaginosa RCL-11. Process Biochem 48:803-809. https://doi.org/10.1016/j. procbio.2013.04.006

Kirk PL (1950) Kjeldahl method for total nitrogen. Anal Chem 22(2):354-358

Kot AM, Błażejak S, Kurcz A, Gientka I (2015) Drożdże jako potencjalne źródło tłuszczu mikrobiologicznego. Post Mikrobiol 54:364-373

Kot AM, Błażejak S, Kurcz A, Gientka I, Kieliszek M (2016) Rhodotorula glutinis - potential source of lipids, carotenoids, and enzymes for use in industries. Appl Microbiol Biotechnol 100:6103-6117. https://doi.org/10.1007/s00253-016-7611-8

Kot AM, Błażejak S, Kurcz A, Bryś J, Gientka I, Bzducha-Wróbel A, Maliszewska M, Reczek L (2017) Effect of initial pH of medium with potato wastewater and glycerol on protein, lipid and carotenoid biosynthesis by Rhodotorula glutinis. Electron J Biotechnol 27:25-31. https://doi.org/10.1016/j.ejbt.2017.01.007

Kot AM, Błażejak S, Gientka I, Kieliszek M, Bryś J (2018) Torulene and torularhodin: "New" fungal carotenoids for industry? Microb Cell Fact 17:49. https://doi.org/10.1186/s12934-018-0893-z

Kot AM, Błażejak S, Kieliszek M, Gientka I, Bryś J (2019) Simultaneous production of lipids and carotenoids by the red yeast Rhodotorula from waste glycerol fraction and potato wastewater. Appl Biochem Biotechnol. https://doi.org/10.1007/s12010-019-03023-Z

Li C, Zhang N, Li B, Xu Q, Song J, Wei N, Wang W, Zou H (2017) Increased torulene accumulation in red yeast Sporidiobolus pararoseus NGR as stress response to high salt conditions. Food Chem 237:1041-1047. https://doi.org/10.1016/j.foodchem.2017.06.033

Marova I, Carnecka M, Halienova A, Certik M, Dvorakova T, Haronikova A (2012) Use of several waste substrates for carotenoid-rich yeast biomass production. J Environ Manag 95:338-342. https:// doi.org/10.1016/j.jenvman.2011.06.018

Martin A, Lu C, Patel T (1993) Growth parameters for the yeast Rhodotorula rubra grown in peat extracts. J Ferm Bioeng 76(4):321325. https://doi.org/10.1016/0922-338X(93)90202-J

Milchert E, Goc W, Lewandowski G, Myszkowski J (1995) Dehydrochlorination of glycerol dichlorohydrin to epichlorohydrin. Chem Pap 49(3):133-136

Miller GL (1959) Use of dinitrosalicylic acid reagent for determination of reducing sugar. Anal Chem 31(3):426-428

Mohammed DM, Abd El Zaher FH, Hassan EA, Abd El Maksoud HK, Ramadan EM (2018) Factors affecting microbial oil accumulation 
by oleaginous yeast. Annu Res Rev Biol 23(2):1-12. https://doi. org/10.9734/ARRB/2018/38425

Moliné M, Libkind D, Diéguez MC, van Broock M (2009) Photoprotective role of carotenoids in yeasts: response to UV-B of pigmented and naturally-occurring albino strains. J Photochem Photobiol B 95(3):156-161. https://doi.org/10.1016/j.jphotobiol .2009.02.006

Nasrabadi MRN, Razavi SH (2011) Optimization of $\beta$-carotene production by a mutant of the lactose-positive yeast Rhodotorula acheniorum from whey ultrafiltrate. Food Sci Biotechnol 20(2):445454. https://doi.org/10.1007/s10068-011-0062-1

Rozporządzenie Ministra Środowiska z dnia 18 listopada 2014 r. w sprawie warunków, jakie należy spełnić przy wprowadzaniu ścieków do wód lub do ziemi, oraz w sprawie substancji szczególnie szkodliwych dla środowiska wodnego. Dz. U. 2014 poz. 1800

Sakaki H, Nakanishi T, Tada A, Miki W, Komemushi S (2001) Activation of torularhodin production by Rhodotorula glutinis using weak white light irradiation. J Biosci Bioeng 92(3):294-297. https ://doi.org/10.1016/S1389-1723(01)80265-6

Sigler K, Chaloupka J, Brozmanova J, Stadler N, Höfer M (1999) Oxidative stress in microorganisms. Folia Microbiol 44(6):587-624. https://doi.org/10.1007/BF02825650

Simpson KL, Nakayama TOM, Chichester CO (1964) Biosynthesis of yeast carotenoids. J Bacteriol 88(6):1688-1694
Suutari M, Liukkonen K, Laakso S (1990) Temperature adaptation in yeasts: the role of fatty acids. J Gen Microbiol 136(8):1469-1474. https://doi.org/10.1099/00221287-136-8-1469

Vijayalakshmi G, Shobha B, Vanajakshi V, Divakar S, Manohar B (2001) Response surface methodology for optimization of growth parameters for the production of carotenoids by a mutant strain of Rhodotorula gracilis. Eur Food Res Technol 213(3):234-239. https://doi.org/10.1007/s002170100356

Zhang G, French WT, Hernandez R, Alley E, Paraschivescu M (2011) Effects of furfural and acetic acid on growth and lipid production from glucose and xylose by Rhodotorula glutinis. Biomass Bioenergy 35(1):734-740. https://doi.org/10.1016/j.biomb ioe.2010.10.009

Zhang Z, Zhang X, Tan T (2014) Lipid and carotenoid production by Rhodotorula glutinis under irradiation/high-temperature and dark/ low-temperature cultivation. Bioresour Technol 157:149-153. https://doi.org/10.1016/j.biortech.2014.01.039

Publisher's Note Springer Nature remains neutral with regard to jurisdictional claims in published maps and institutional affiliations. 